\title{
Determinação espectrofotométrica de glifosato em cabelo humano utilizando complexação com Ca2+
}

\author{
Spectrophotometric determination of glyphosate in human hair using complexation with Ca2 + \\ Ludmila Jordão Santos ${ }^{\dagger}$, Pâmela de Oliveira Mello", Cristiani Hertel§ ${ }^{\S}$, Carlos Eduardo Cardoso ${ }^{\| *}$
}

Como citar esse artigo. Santos, LJ; Mello, PO; Hertel, C; Cardoso, CE. Determinação espectrofotométrica de glifosato em cabelo humano utilizando complexação com Ca2+. Revista Teccen. 2018 Jan/Jun.; 11 (1): 54-60.

\begin{abstract}
Resumo
Muitas substâncias químicas, tais como os agroquímicos, geram efeitos tóxicos no homem. Um bom exemplo é a $\mathrm{N}$-[(fosfonometil) glicina], comercialmente conhecida como glifosato e muito utilizada em regiões agrícolas. Em todos os casos, após exposição, estes compostos atingem a corrente sanguínea e são incorporados ao fio de cabelo, podendo ser identificados e quantificados. Assim, como o cabelo humano é considerado um dosímetro biológico, este trabalho teve como objetivo otimizar os processos de lavagem e digestão de amostras de cabelo para posterior quantificação de glifosato utilizando a espectrofotometria. Os experimentos mostraram que a determinação espectrofotométricada molécula complexada pode ser utilizada para quantificar glifosato na matriz capilar. As curvas analíticas apresentaram um r2 maior que 0,9900 e os testes de recuperação situaram-se entre 90 e $110 \%$, indicando que as metodologias desenvolvidas podem ser aplicadas com sucesso. Ótimos resultados foram obtidos partindo-se da reação do glifosato com o dissulfeto de carbono a 1\%. Nessa reação, o grupo amino do glifosato foi convertido em ácido ditiocarbâmico que, após quelado com o íon $\mathrm{Ca} 2+$, teve a absorbância medida em um espectrofotômetro a $435 \mathrm{~nm}$.

Palavras-Chave: Cabelo; Glifosato; Análise espectrofotométrica; Complexação com Ca2+.
\end{abstract}

\begin{abstract}
Many chemicals, such as agrochemicals, generate toxic effects in humans. A good example is N - [(phosphonomethyl) glycine], commercially known as glyphosate and widely used in agricultural regions. In all cases, upon exposure, these elements reach the bloodstream and are incorporated into the hair and can thus be identified and quantified. Thus, as human hair is considered a biological dosimeter, this work aimed to optimize the washing and digestion processes of hair samples for further quantification of glyphosate using spectrophotometry. The experiments showed that the spectrophotometry preceded by the complexation of the molecule can be used to quantify glyphosate in the capillary matrix. The analytical curves presented a r2 greater than 0.9900 and the recovery tests were between 90 and $110 \%$, indicating that the methodologies developed can be applied successfully. Excellent results were obtained starting from the reaction of the glyphosate with the $1 \%$ carbon disulfide. In this reaction, the amino group of glyphosate was converted to dithiocarbamic acid which, after chelating with the $\mathrm{Ca} 2+$ ion, had the absorbance measured in a spectrophotometer at $435 \mathrm{~nm}$.

Keywords: Hair, Glyphosate, Spectrophotometric analysis, Complexation with $\mathrm{Ca} 2+$.
\end{abstract}

\section{Introdução}

O Glifosatopossui fórmula molecular $\mathrm{C}_{3} \mathrm{H}_{8} \mathrm{NO}_{5} \mathrm{Pe}$ pertence ao grupo químico das glicinas substituídas, sendo classificado como herbicida de uso agrícola confirmado de classe toxicológica I (Amarante Junior et al., 2002).

O Glifosato é largamente utilizado devido a sua capacidade de remover as ervas daninhas antes do plantio propriamente dito, desde que foi introduzido no mercado, o uso do herbicida glifosato tornou-se prática frequente, representando mais de $60 \%$ do mercado mundial de herbicidas não seletivos (Amarante Junior et al., 2002).
A maioria dos agrotóxicos são compostos orgânicos e hidrofóbicos que tendem a se adsorver em partículas suspensas e matéria orgânica dissolvida e assim acumular-se em sedimentos e na biota aquática (Sucahyo et al., 2008).

Existem vários métodos de quantificação do glifosato, sendo as mais utilizadas a cromatografia em fase gasosa, a cromatografia líquida de alta eficiência (CLAE), a cromatografia de troca iônica, a cromatografia em camada delgada, a ressonância magnética nuclear de fósforo $31\left(\mathrm{RMN}^{31} \mathrm{P}\right)$, a polarografia, a eletroforese e a espectrofotometria. (Queiroz et al., 2011)

Jan et al. (2009) usaram a reação do glifosato com o dissulfeto de carbono a $1 \%$ e o complexaram

\footnotetext{
Afiliação dos autores: † Universidade de Vassouras, Curso de Engenharia Química, Vassouras-RJ, Brasil;

\$ Biomédica;

§ Química Industrial, Laboratório de Química da Universidade de Vassouras, Vassouras-RJ, Brasil;

|| Universidade de Vassouras, Curso de Mestrado Profissional em Ciências Aplicadas em Saúde, Vassouras-RJ, Brasil.

* Email para correspondencia: cardoso221@yahoo.com.br
} 
com o íon cobre. Nessa reação, o grupo amino do agroquímico foi convertido em ácido ditiocarbâmico que, após quelado com o íon $\mathrm{Cu}^{2+}$ teve a absorbância medida em um espectrofotômetro a $435 \mathrm{~nm}$.

Os resultados da primeira análise de cabelo foram publicados por Hoppe em 1858, que determinou Arsênio (As) no cabelo de cadáveres exumados onze anos após o sepultamento. Aproximadamente 100 anos depois, em 1954, Goldblum determinou anfetamina em pelos de cobaia. E em 1979, Baumgartner determinou a concentração de opiáceos no cabelo humano, através de extração com metanol e detecção por Radioimunoensaio (RIA) (Pozebon, Dressler \& Curtius, 1999).

Ainda neste mesmo trabalho, Curtiuset al. (1999) comentam que o cabelo poderia ser usado como material de biópsia para a determinação de elementos traço presentes no corpo humano, já que funciona como um órgão excretor. Durante as décadas seguintes as análises de sangue e urina tiveram a preferência e na década de 1930 iniciou-se o diagnóstico de doenças através de exames laboratoriais. Nos anos 60, a utilidade da análise de cabelo foi redescoberta por pesquisadores da área de nutrição, e na década seguinte foram realizados vários simpósios a respeito do assunto e livros foram publicados (Pozebon, Dressler \& Curtius, 1999).

Para quantificação em cabelo humano, foi desenvolvido e validado um método de extração e de analise espectrofotométrica.

Este foi o ponto de partida utilizado nesse trabalho e diversos testes foram conduzidos no sentido de otimizar os volumes e as concentrações dos reagentes para a formação do complexo amarelo Glifosato - Metal.

$\mathrm{O}$ trabalho propõe a utilização do íon $\mathrm{Ca}^{2+}$ na reação de complexação proposta por Jane colaboradores (2009). A figura 1 mostra a reação ocorrendo da mesma forma que com o íon $\mathrm{Cu}^{2+}$.

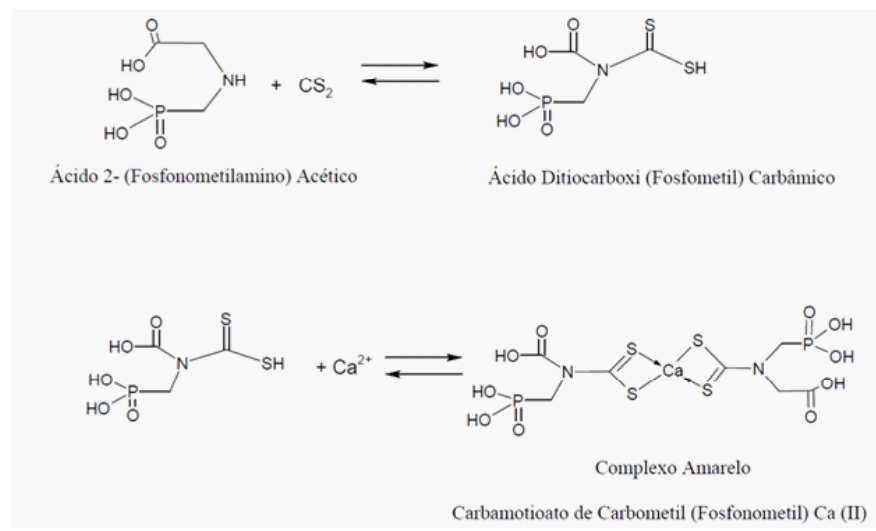

Figura 1. Representação esquemática da reação de complexação utilizada.

\section{Materiais e métodos}

\section{Amostras de cabelo}

Após a submissão ao Comitê de Ética em Pesquisa da USS (número de CAAE 07252512.0.0000.5290), vide anexo, as amostras da matriz capilar foram obtidas da região póstero-inferior de crânio, abrangendo a área referente ao osso occipital, onde cortaram-se os fios de cabelo próximo ao couro cabeludo. Esses fios foram doados pelo próprio grupo de pesquisa $(\mathrm{n}=6)$.

\section{Soluções e reagentes}

Todos os reagentes utilizados apresentavam,

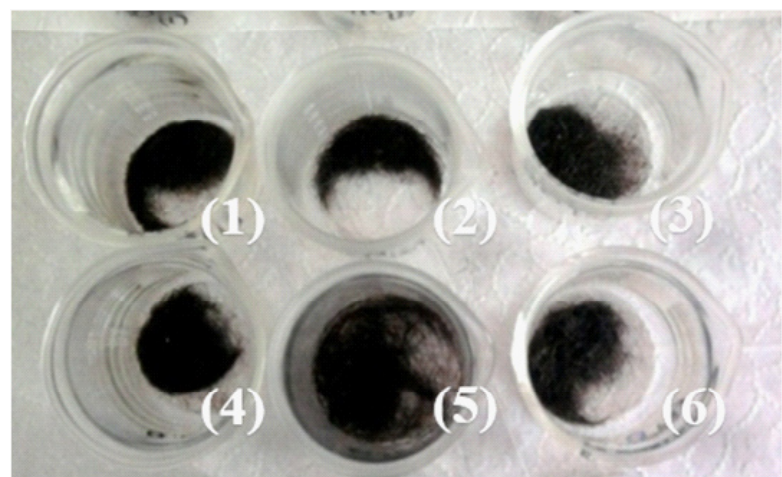

Figura 2. Amostras de cabelo in natura $(\mathrm{n}=6)$. 
no mínimo, grau analítico. Ácido nítrico concentrado $\left(\mathrm{HNO}_{3}\right)$ da Cromaline (Brasil), hidróxido de sódio $(\mathrm{NaOH})$ a $30 \%(\mathrm{~m} / \mathrm{V})$ da Vetec (Brasil), glifosato comercial a $48 \%(\mathrm{~m} / \mathrm{V})$, dissulfeto de carbono $\left(\mathrm{CS}_{2}\right)$ da FlukaChemika (França) e cloreto de cálcio $\left(\mathrm{CaCl}_{2}\right)$ PA da Reagen (Brasil), etanol PA (Merck), Lauril Sulfato de Sódio $1 \%(\mathrm{~m} / \mathrm{V})$ da Merck (Brasil), acetona PA (Cromoline, Brasil), e peróxido de hidrogênio 35 volumes $\left(\mathrm{H}_{2} \mathrm{O}_{2}\right)$ da Cromoline (Brasil),foram utilizados no preparo das soluções e dos complexos, para lavagem, extração e digestão das amostras

Para o preparo das soluções de $\mathrm{CS}_{2}$ 1\% (100 $\mathrm{mL}$ ) utilizou-se clorofórmio para avolumar, para as de cloreto de cálcio $\left(215 \mu \mathrm{g} \cdot \mathrm{mL}^{-1} \mathrm{Ca}^{2+}, 50 \mathrm{~mL}\right)$ e para as de cloreto de cálcio $\left(10000 \mu \mathrm{g} \cdot \mathrm{mL}^{-1} \mathrm{Ca}^{2+}, 50 \mathrm{~mL}\right)$, nitrato de cobre $\left(10000 \mu \mathrm{g} \cdot \mathrm{mL}^{-1} \mathrm{Cu}^{2+}, 50 \mu \mathrm{mL}\right)$, avolumou-se com água destilada.

\section{Lavagem das amostras de cabelo}

Neste trabalho, cerca de $0,5 \mathrm{~g}$ de cabelo foram cortados em pedaços de cerca de 1,0 mm. A massa de cabelo foi mantida em uma solução de lauril sulfato de sódio $1 \%(\mathrm{~m} / \mathrm{V})$ por 30 minutos e, em seguida, filtradas em papel filtro. Após filtração, a massa foi lavada duas vezes com água destilada (10 minutos cada lavagem) e deixada em repouso em $75 \mathrm{~mL}$ de acetona por 10 minutos. Finalmente, a massa foi lavada com água destilada por 5 minutos, filtrada e seca em estufa a 105 ${ }^{\circ} \mathrm{C}$ por 2 horas. Todas as operações foram realizadas sob agitação, exceto a secagem.

\section{Digestão do cabelo}

Após atingir a temperatura ambiente em dessecador, foi realizada a digestão. As amostras foram digeridas de forma ácida e alcalina, portanto o teste foi repetido duas vezes. Para digestão alcalina em cada tubo foi adicionado $0,25 \mathrm{~g}$ de cabelo lavado e $3,5 \mathrm{~mL}$ $\mathrm{NaOH} 30 \%$, agindo durante 15 minutos. E para a ácida $0,25 \mathrm{~g}$ de cabelo lavado e $3,0 \mathrm{~mL} \mathrm{H}_{2} \mathrm{O}_{2} 35 \%$ e $0,5 \mathrm{~mL}$ $\mathrm{HNO}_{3}$ por 30 minutos. Todos os procedimentos foram realizados em frasco aberto numa temperatura de 80 ${ }^{\circ} \mathrm{C}$.

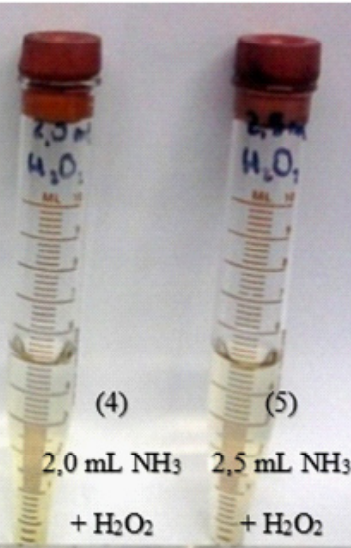

$+\mathrm{H}_{2} \mathrm{O}_{2}$

Figura 3. Digestão ácida.

\section{Preparo da curva analítica}

Foram preparados 6 tubos com a solução padrão da digestão alcalina, contendo $0,25 \mathrm{~g}$ cabelo $+3,5 \mathrm{~mL}$ $\mathrm{NaOH} 30 \%$,uma foi utilizada como branco, adicionando $10 \mu \mathrm{L}$ de água destilada para zerar o equipamento,e em cada um dos outros cinco tubos de teste foram adicionados a solução padrão junto com as alíquotas da solução de $\mathrm{N}$-[(fosfonometil) glicina] $48 \%(\mathrm{~m} / \mathrm{V})$ de $10,20,30,40$ e $50 \mu \mathrm{L}$, respectivamente para cada teste.
Da mesma forma foi realizado para a digestão ácida, entretanto a solução padrão da digestão ácida é feita com 0,25 g cabelo $+3,0 \mathrm{~mL} \mathrm{H}_{2} \mathrm{O}_{2} 35 \%+0,5 \mathrm{~mL} \mathrm{HNO}_{3}$ concentrado, o procedimento de preparo dos outros tubos de testes e o branco foi o mesmo.

Assim os testes de recuperação foram feitos para digestão ácida e alcalina, em amostras fortificadas com os analítos de interesse em concentrações localizadas na região central das curvas.

Dessa forma seguiu para a reação de complexação, 
que ocorreu da mesma forma para ambos tipos de digestão, onde foi adicionado $1 \mathrm{~mL}$ da solução filtrada em um tubo de ensaio, junto com $5 \mathrm{~mL}$ de $\mathrm{CS}_{2} 1 \%$ seguido por agitação durante 30 segundos depois foi acrescentado $100 \mu \mathrm{L}$ de $\mathrm{CaCl}_{2} 10000 \mu \mathrm{L}$. $\mathrm{mL}^{-1}$ e agitado por mais 15 segundos. Assim resulta em uma solução de suas fases, a fase orgânica foi avolumada com álcool etílico para $10 \mathrm{~mL}$. A reação de complexaçãoe suas variáveis como tempo foi seguida de acordo com aadaptação de JAN et al., 2009. Após avolumar, umaquantidade suficiente da solução foi adicionada a cubeta e para realização da leitura espectrofotométrica.

\section{Resultados e discussão}

Após a exposição do homem à determinadas substâncias químicas, podem ocorrer processos de absorção, distribuição, metabolismo e eliminação das mesmas e dos respectivos produtos, pela biotransformação do organismo. $\mathrm{O}$ conhecimento desses parâmetros define a escolha do material (matriz) que irá constituir a matriz analítica para a análise de determinadas substâncias.

A utilização de fluídos biológicos é universalmente aceita para o diagnóstico de uso de drogas, porém, tradicionalmente, amostras de sangue ou urina têm sido mais comumente usadas nesta detecção. Entanto o avanço tecnológico permitiu a detecção da presença dos níveis relativamente baixos de drogas e metabólitos presentes em amostras de cabelo e então os testes nesta matriz começaram a ser utilizados rotineiramente nos anos 70 nos EUA onde seu uso expandiu nos anos 80 e logo a seguir foram introduzidos na Europa (Tsanaclis \& Wicks, 2007).

Com isso, nas duas últimas décadas houve um aumento no estudo e caracterização do uso de drogas, e alguns agroquímicos através da análise em cabelo com a consequente publicação de vários estudos e revisões científicas com este intuito (Jurado-Montoro, 2007).

Segundo Carneiro et al. (2002), contaminantes são incorporados no cabelo através de diferentes fontes e mecanismos endógenos e exógenos. As fontes endógenas são as mais importantes quando se deseja fazer uma avaliação do estado de saúde de um indivíduo, no que diz respeito a anomalias fisiológicas, desequilíbrio nutricional ou intoxicação ambiental.

Assim, para remover este material não endógeno, o cabelo destinado à análise foi lavado eficientemente, já que a sujeira pode falsear os resultados. Atualmente, o método de lavagem desenvolvido pela Agência Internacional de Energia Atômica (IAEA) é utilizado em diversos laboratórios. Este método consiste em lavar $0,5 \mathrm{~g}$ de cabelo uma vez com acetona, três vezes com água e uma vez com acetona, deixando-se entre cada lavagem o cabelo recoberto com o solvente, à temperatura ambiente e sob agitação. Ao término, a massa de cabelo é seca durante a noite envolvida em papel filtro de grau cromatográfico (Pozebon, Dressler \& Curtius, 1999). Com isto, o tempo de execução torna-se muito alto, inviabilizando o procedimento assim como outras metodologias já existentes. Além disso, muitos estudos demonstram certa discrepância nos resultados obtidos devido a utilização de reagentes capazes de interferir na matriz a ser estudada.

Com base nestes dados, este trabalho buscou uma otimização da lavagem e secagem eficaz e rápida utilizando reagentes que não gerassem discrepâncias e danos à matriz e que conseguisse eliminar os compostos exógenos. Neste propósito, foram realizados diversos estudos em relação às substâncias comumente utilizadas para este fim e após análise das mesmas, viu-se que a combinação entre Lauril Sulfato Na 1\%, água destilada e acetona mostraram-se satisfatórias. Tal procedimento possibilitou realizar a operação de lavagem por 5 horas sem danificar a amostra para a subsequente quantificação dos analitos.

\section{A digestão Capilar}

A digestão da matriz capilar serve para a liberação dos compostos endógenos para o meio externo, permitindo assim sua quantificação, ela pode ser feita em meio ácido ou alcalino. A hidrólise alcalina é usualmente empregada para a determinação de compostos orgânicos, a dissolução feita com hidróxido de tetrametilamônio (TMAH) tem a vantagem de minimizar a perda de compostos importantes que possam ser voláteis, tornado a analise adequada por espectrometria de absorção atômica eletrotérmica (ETAAS), vaporização eletrotérmica acoplada ao ICP de massa (ETV-ICP-MS) e vaporização eletrotérmica com plasma indutivamente acoplado (ETV-ICP-AES) (Pozebon, Dressler \& Curtius, 1999).

Segundo Pozebon e colaboradores, a digestão ácida por sua vez é a mais abrangente, a reação pode ocorrer em meio aberto ou fechado, os ácidos normalmente utilizados são o $\mathrm{HNO}_{3}, \mathrm{HCl}, \mathrm{H}_{2} \mathrm{SO}_{4}$, $\mathrm{HClO}_{4}$ e $\mathrm{HF}$. Dessa forma o $\mathrm{HClO}_{4}$ mostra-se capaz de remover a matéria orgânica, enquanto o HF remove a sílica, todavia o procedimento de digestão da amostra de cabelo deve ser otimizado de acordo com a técnica de medida a ser utilizada, assim para os tipos de analises variadas, a combinação de $\mathrm{HNO}_{3}$ e $\mathrm{H}_{2} \mathrm{O}_{2}$ (3:1) tem sido a mais utilizada. Em contrapartida o tipo de abordagem, utilizando a espectrofotometria, ainda não foi referenciado na literatura.

Para os testes, buscou-se utilizar um menor volume de ácido nítrico concentrado a fim de reduzir os danos aos compostos endógenos a serem estudados. Com isso, o melhor resultado obtido foi uma digestão 
realizada em copo de becker contendo $0,25 \mathrm{~g}$ de cabelo lavado, $3,0 \mathrm{~mL}$ de $\mathrm{H}_{2} \mathrm{O}_{2} 35 \%, 0,5 \mathrm{~mL}$ de $\mathrm{HNO}_{3}$. Adigestão completa ocorreu num tempo máximo de 30 minutos e a amostra digerida como visto na figura 1 foi filtrada em papel filtro e recolhida em um balão volumétrico de $50 \mathrm{~mL}$, obtendo-se uma amostra límpida e clara após a digestão, como pode ser visto na figura 3 .

Um estudo realizado por Dulaurent et al. (2007) possibilitou determinar a presença dos agroquímicos Alachlore Carbofuran em cabelo de dois indivíduos através de métodos cromatográficos. Para o preparo das amostras foi necessário uma hidrólise de 16 horas em tampão específico para em seguida realizar a separação da fase orgânica. No presente trabalho, um procedimento bem mais simples foi otimizado e o tempo total de execução não ultrapassa 5 horas, devido aos processos de lavagem, digestão e complexação.

A digestão ácida utilizou perxido de hidrogênio $35 \%$ e ácido nítrico concentrado, possivelmente destruindo a molécula do glifosato e impossibilitando a formação do complexo, enquanto a alcalina demonstrouse eficiente (hidróxido de sódio $30 \%$ ). Tal procedimento foi capaz de digerir a matriz capilar sem danificar a molécula do analito. $\mathrm{O} \mathrm{pH}$, neste caso, situou-se na faixa de 11 a 12, permitindo a formação do complexo colorido, crucial na quantificação por espectrofotometria.

\section{A complexação da molécula de glifosato:}

Jan e colaboradores (2009) usaram a reação do glifosato com o dissulfeto de carbono a $1 \%$ e o complexaram com o íon cobre. O complexo formado teve a absorbância medida em um espectrofotômetro a $435 \mathrm{~nm}$. Este foi o ponto de partida utilizado em um outro trabalho realizado, onde junto com SCHMIDT, G. B.; SANTOS, L. J.; LEITE, J. M. C. conduzimos testes no sentido de otimizar os volumes e as concentrações dos reagentes para a formação do complexo Glifosato Metal, utilizando-se o cálcio como complexante. Assim, preliminarmente, fez-se reagir $1,0 \mathrm{~mL}$ de glifosato a $1 \%(\mathrm{~m} / \mathrm{V})$ com volumes variáveis de CS2 a $1 \%(1$ a
$5 \mathrm{~mL}$ ), objetivando-se converter o grupo amino do agrotóxico em ácido ditiocarbâmico. O ácido formado foi complexado com volumes variáveis $(100 \mu \mathrm{L}$ a 1000 $\mu \mathrm{L}$ ) de uma solução de Ca2+ $1000 \mu \mathrm{g}$ mL-1 em pH 12,0. A N[(fosfonometil) glicina] (glifosato) é um agrotóxico peculiar que depende principalmente do $\mathrm{pH}$, pois este é capaz de mudar sua conformação molecular, dificultando sua análise em amostras de solo e água. Em $\mathrm{pH}$ abaixo de 0,8 , a maior parte do glifosato se apresenta com uma protonação no sítio da amina. Em pH 0,8, cerca de 50\% das moléculas apresentam uma protonação e as demais moléculas com uma dissociação no grupo fosfato. A partir deste valor até $\mathrm{pH} 2,2$, tem-se predominância da forma molecular, com uma dissociação (-PO2H-) e uma protonação (-NH2+-), sendo que, em $\mathrm{pH} 2,2$, $50 \%$ do composto já possui duas dissociações, embora mantenha a protonação no grupamento amina. Entre $\mathrm{pH}$ 2,2 e 5,4, o herbicida se mostra com predominância da forma com duas dissociações, tendo, do mesmo modo, $50 \%$ das moléculas com três dissociações em pH 5,5. A partir de pH 5,5 até 10,2, têm-se três dissociações. Neste $\mathrm{pH}$ ocorrem as formas com três e quatro dissociações. Acima de $\mathrm{pH} 11$ o glifosato se apresenta totalmente dissociado. Tal comportamento justifica, portanto, porque os experimentos de complexação com $\mathrm{Ca} 2+$ foram conduzidos em $\mathrm{pH} 12$.

Contudo, a molécula nessas condições se mostra muito instável, assim foram avaliadas além do $\mathrm{pH}$, outras a variáveis, como o tempo que é fundamental para respeitar a dissociação da molécula, onde constatouse que em tempo superior a 15 minutos de ocorrência da complexação ela degrada, e nota-se também quea exposição a luz traz discrepância na solução e insere erros na leitura por espectrofotometria de absorção.

Assim estes estudos preliminares mostraram bons resultados e indicaram que os volumes de $5 \mathrm{~mL}$ de $\mathrm{CS}_{2} \mathrm{e}$ $1 \mathrm{~mL}$ de $\mathrm{Ca}_{2}$ em pH 12,0, são excelentes, considerando a solução mantida em repouso no escuro por quinze minutos e a fase orgânica separada e avolumada com etanol para $10 \mathrm{~mL}$, foi possível produziras maiores leituras de absorbância.

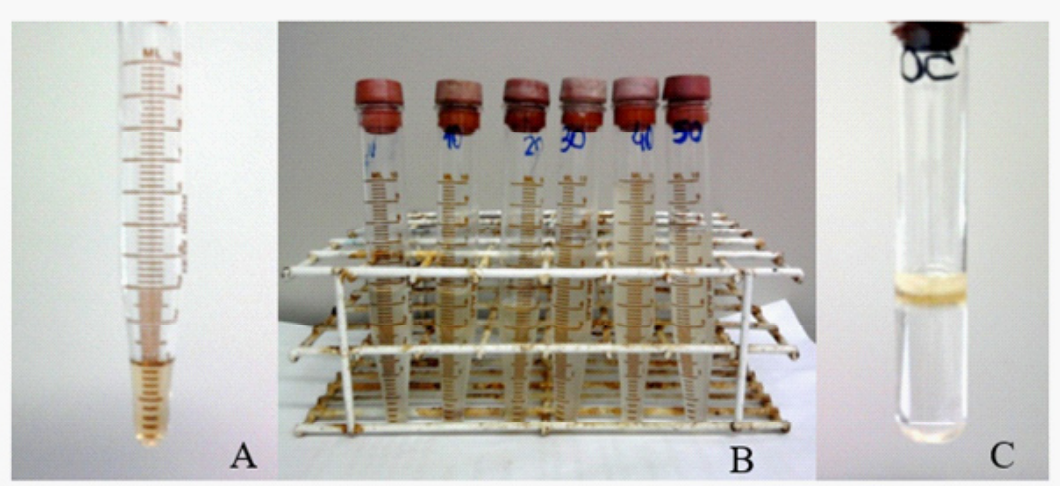

Figura 4. Etapas de (A) digestão, (B) complexação e (C) amostras avolumadas para leitura da N[(fosfonometil) glicina). 


\section{Teste de recuperação do analito}

Os testes de recuperação do analito podem ser estimados pela análise de amostras fortificadas com quantidades conhecidas do mesmo (spike). As amostras foram fortificadas com o analito em três diferentes concentrações: de 10,30 , e $50 \mu \mathrm{L}$, dentro da faixa de uso do método.

Alimitação deste procedimento é a de que o analito adicionado não está necessariamente na mesma forma

$$
\left.R(\%)=\frac{C_{1}-C_{2}}{C_{3}}\right] \times 100
$$

\footnotetext{
Sendo:

$\mathrm{C}_{1}=$ concentração do analito na amostra fortificada,

$\mathrm{C}_{2}=$ concentração do analito na amostra não fortificada,

$\mathrm{C}_{3}=$ concentração do analito adicionada à amostra fortificada.
}

que a presente na amostra, podendo levar a resultados falsamente otimistas. O cálculo da recuperação pode ser feito com base na Equação 1:

Normalmente, a determinação de agroquímicos em amostras diversas é feita utilizando metodologias bem estabelecidas e tradicionais como a cromatografia de extração (líquido-líquido ou gasosa-gasosa, cromatografia líquida por espectrometria de massa) e análise de ativação de nêutrons, elevando os custos e o tempo de execução já que que as amostras precisam de um tratamento mais elaborado.

Os métodos espectroscópicos baseiam-se na absorção e/ou emissão de radiação eletromagnética por muitas moléculas, quando os seus elétrons se movimentam entre níveis energéticos, permitindo comparar a radiação absorvida ou transmitida por uma solução que contém uma quantidade desconhecida de soluto, com uma quantidade conhecida da mesma substância. A espectrofotometria baseia-se, portanto, na absorção da radiação nos comprimentos de onda que corresponde a uma gama de comprimentos de onda que vai desde o ultravioleta ao infravermelho no espectro da radiação eletromagnética. O espectro visível está contido essencialmente na zona entre 400 e $800 \mathrm{~nm}$. Um espectrofotômetro UV/vis é um aparelho que faz passar um feixe de luz monocromática através de uma solução, e mede a quantidade de luz que foi absorvida por essa solução. Usando um prisma o aparelho separa a luz em feixes com diferentes comprimentos de onda (tal como acontece no arco-íris com a separação das cores da luz branca). Pode-se assim fazer passar através da amostra um feixe de luz monocromática (de um único comprimento de onda, ou quase). O espectrofotômetro permite-nos saber que quantidade de luz é absorvida a cada comprimento de onda.

Diferentes substâncias têm diferentes padrões de absorção, a espectrofotometria permite-nos, por exemplo, identificar substâncias com base no seu espectro. Permite também quantificá-las, uma vez que a quantidade de luz absorvida está relacionada com a concentração da substância.

O glifosato possui em sua estrutura um grupo amina que foi convertido em ácido ditiocarbâmico após a reação com o dissulfeto de carbono. Este ácido em contato com o íon metálico cálcio $\left(\mathrm{Ca}^{2+}\right)$ gerou um complexo amarelo cuja intensidade da coloração foi proporcional a concentração do analito na amostra (absorbâncias lidas a $435 \mathrm{~nm}$ ).

Este estudo espectrofotométrico teve como ponto de partida o trabalho de Jan et al. (2009) que usaram a reação do glifosato com o dissulfeto de carbono a $1 \% \mathrm{e}$ o complexaram com o íon cobre.

Neste trabalho, utilizou-se a complexação desenvolvida pelo Grupo de Pesquisas do Laboratório de Química Analítica Aplicada (LAQAp) da Universidade de Vassouras, com outros metais, como ferro, manganês, cromo e cálcio (Schmidt, 2014). A complexação que obteve o melhor resultado foi a realizada com cálcio, também levando a formação de um complexo amarelo que foi separado, avolumado para $10 \mathrm{~mL}$ com álcool etílico e levado a um espectrofotômetro UV/vis para leitura a $435 \mathrm{~nm}$ (Figura 4).

A curva analítica construída para diferentes concentrações de glifosato em cabelo pode ser vista na Figura 5 e o teste de recuperação, na tabela 1 .

Tabela1. Testes de recuperação de N-[(fosfonometil) glicina

\begin{tabular}{ccc}
\hline Massa adicionada & Massa encontrada & Recuperação (\%) \\
$0,01656 \mathrm{~g}$ & $0,01590 \pm 6,7 \times 10^{-4}$ & 96 \\
$0,00746 \mathrm{~g}$ & $0,007421 \pm 4,32 \times 10^{-5}$ & 99 \\
\hline
\end{tabular}




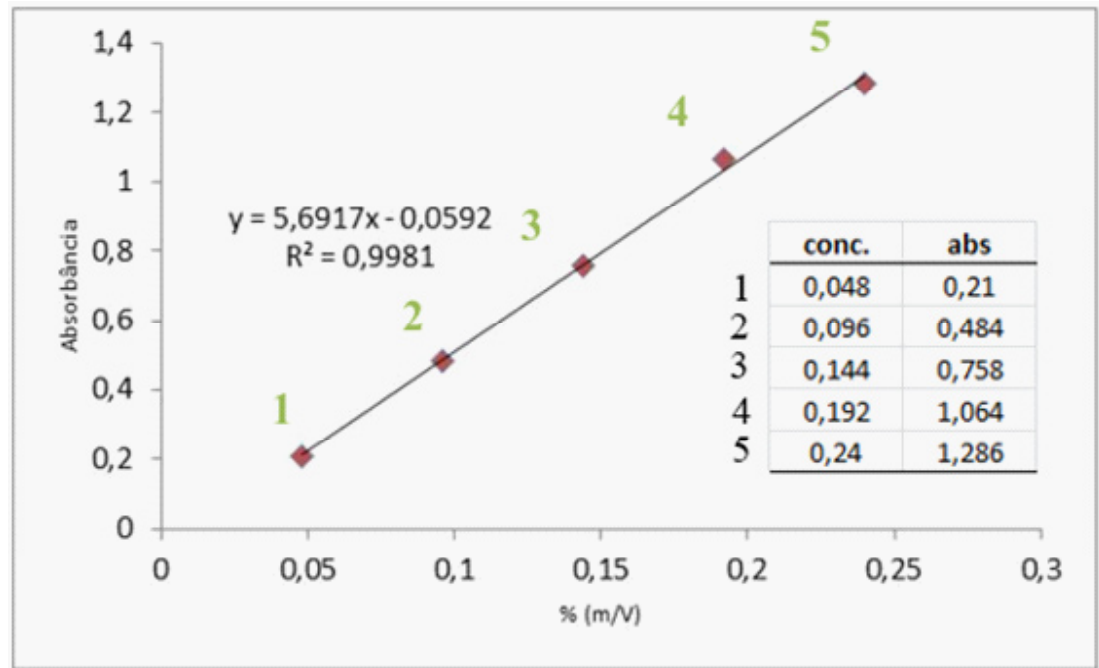

Figura 5. Curva analítica para o glifosato.

\section{Conclusões}

É possível quantificar glifosato utilizando a espectrofotometria UV/vis em amostras de cabelo humano, desde que uma complexação prévia seja feita. O complexo glifosato-metal, por absorver na região do visível, pode ser usado na quantificação deste, uma vez que a Lei de Beer é obedecida na faixa de trabalho ora estudada.

Adicionalmente, o preparo de amostras de cabelo humano para quantificação de glifosato, pode ser otimizado e realizado em menor tempo que os já descritos na literatura. $\mathrm{O}$ procedimento foi mais rápido e tão eficiente quanto o adotado internacionalmente.

Conclui-se, portanto, que a metodologia alternativa pode ser aplicada com baixo custo e boa eficiência para identificação de glifosato em cabelo humano. Com isso, se torna altamente acessível para ser aplicada em laboratórios de diagnóstico e pesquisa.

\section{Referências}

AMARANTE JUNIOR, Ozelito. (2002). Possidônio de et al.. Glifosato: propriedades, toxicidade, usos e legislação. Química Nova, São Paulo, v. 25 , n. 4 , jul.

CARNEIRO, Maria Tereza W.D. et al.. (2002). Intervalos de referência para elementos menores e traço em cabelo humano para a população da cidade do Rio de Janeiro - Brasil. Química Nova, São Paulo, v. 25, n. 1, Feb.

DULAURENT, S et al. (2008).. Hair analysis to document non-fatal pesticide intoxication cases. Forensic Science International 176 72-75.

G. B. SCHMIDT. (2014). Avaliação qualitativa e quantitativa de glifosato em área rural de Paty do Alferes e Vassouras - RJ, Vassouras, Universidade Severino Sombra.

G. B. SCHMidT, L. J. SANTOS, J. M. C. LEITE, B. A. JORDÃO, D. M. TORRES e C.E. CARDOSO. (2015). Desenvolvimento de método espectrofotométrico para determinação de $n$-[(fosfonometil) glicina] (glifosato) em latossolo de paty do alferes/rj, p. 6793-6800. In: Anais do XX Congresso Brasileiro de Engenharia Química - COBEQ 2014 [=
BlucherChemicalEngineeringProceedings, v.1, n.2]. SãoPaulo: Blucher ISSN 2359-1757, DOI 10.5151/chemeng-cobeq2014-0228-26441-180455

JAN, M. R., SHAH, J., MUHAMMAD, M., ARA, B. (2009). Glyphosate herbicide residue determination in samples of environmental importance using spectrophotometric method.JournalofHazardous Materials,169, $742-745$.

JURADO-MONTORO, C. (2007) Análisis de drogas de abuso enmuestras de pelo: diagnóstico del consumo crônico. TrastornosAdictivos, v. 9, n. 3, p. $172-183$.

POZEBON, D.; DRESSLER, V. L.; CURTIUS, A. J. (1999).Análise de cabelo: uma revisão dos procedimentos para a determinação de elementos traço e aplicações. Química Nova, São Paulo, v. 22, n. 6, Dec.

QUEIROZ, G. M. P., SILVA, M. R., BIANCO, R. J. F. PINHEIRO, A., KAUFMANN, V. (2011). Transporte de glifosato pelo escoamento superficial e por lixiviação em um solo agrícola.Química Nova, Vol. 34, No. 2, 190-195.

SUCAHYO, D. et. al. (2008). Acute toxicity of pesticides to the tropical freshwater shrimp Caridinalaevis.Ecotoxicology and Environmental Safety, v. 69, p. 421-427.

TSANACLIS, L.; WICKS, J.F.C. (2007. Patterns in drug use in the united kingdom as revealed through analysis of hair in a large population sample. Forensic Science International, v. 170, (2-3), p. 121-128.

TSANACLIS, L. M.; WICKS, J. F. C.; CHASIN, A. A. M..Análise de drogas em cabelo ou pêlos. RevInter Revista Intertox de Toxicologia, Risco Ambiental e Sociedade, v. 4, n. 1, p. 06-46, fev. 2011. 